\title{
Application of the Laser Induced Phosphorescence method to the analysis of temperature distribution in heated and evaporating droplets
}

\author{
P.A. Strizhak ${ }^{1}$, R.S. Volkov ${ }^{1}$, D.V. Antonov ${ }^{1}$, G. Castanet ${ }^{2}$, S.S. Sazhin ${ }^{3 *}$ \\ ${ }^{1}$ National Research Tomsk Polytechnic University, 30, Lenin Avenue, 634050, Tomsk, \\ Russia \\ ${ }^{2}$ Université de Lorraine, CNRS-UMR7563, CS 25233, France \\ ${ }^{3}$ Advanced Engineering Centre, School of Computing, Engineering and Mathematics, \\ University of Brighton, Brighton, BN2 $4 G J, U K$
}

August 19, 2020

\begin{abstract}
Results of detailed analysis of temperature fields in droplets of four widely used liquids (water, kerosene, Diesel and gasoline (petroleum oil) fuels) are presented. Single droplets suspended on a wire were heated in a flow of hot air. The initial droplet radii were in the range 1 to $2 \mathrm{~mm}$, air temperature was in the range $20^{\circ} \mathrm{C}$ to $500^{\circ} \mathrm{C}$, air flow velocity was $3-3.5 \mathrm{~m} / \mathrm{s}$. The droplet temperature was measured based on Laser Induced Phosphorescence (LIP). BAM:Eu ( $\left.\mathrm{BaMgAl}_{10} \mathrm{O}_{17}: \mathrm{Eu}^{2+}\right)$ microparticles were introduced into the droplets for the emission of a temperature-sensitive phosphorescent signal. Optical sectioning inside the droplet was performed using a thin laser sheet, while two cameras detected the phosphorescence signal in two spectral bands. A ratiometric approach using the pixel-to-pixel ratio of the images recorded by the two cameras allowed us to determine the local temperature within the heated and evaporating droplet. The range of applicability and the advantages/shortcomings of the method are established alongside the sources of errors. The experimentally observed droplet surface temperatures are compared with the predictions of the customised version of ANSYS Fluent with the Effective Thermal Conductivity (ETC) model implemented into
\end{abstract}

${ }^{*}$ Corresponding author. E-mail: S.Sazhin@brighton.ac.uk 
it via User Defined Functions (UDF). It is shown that ANSYS Fluent can correctly predict the trend of the time evolution of these temperatures.

Keywords:

Laser Induced Phosphorescence, droplets, heating and evaporation, mathematical model, ANSYS Fluent

\section{Introduction}

Temperature measurements at the surfaces of and inside droplets are important for numerous practical applications, including spraying of liquid fuels [1], sprays in internal combustion engines and other combustion devices [2, 3, 4], and spray-based fire extinguishers [5]. These measurements are crucial for understanding many phenomena, including the processes during droplet collisions [6, 7], impact of droplets on hot solid surfaces [ [, 9] and droplet micro-explosions during their heating [10, 11].

One of the widely used approaches to measuring these temperatures is based on contact measurements. The sensitive element of a thermocouple is introduced into the droplet or is brought towards it [12]. This approach is rather straightforward and uses relatively cheap equipment, but it has serious shortcomings, most notably: a) it allows us to perform only localised measurements with a time-response limited by the thermocouple size; b) thermocouples can affect droplet heating (they can be sources and sinks of heat for droplets) and also droplet shape.

A number of contactless optical methods have been suggested for measuring droplet temperatures [13]: laser-induced fluorescence (LIF), laser-induced phosphorescence (LIP), rainbow refractometry, Raman spectroscopy, and infrared thermography. Among these techniques, Laser-induced fluorescence is arguably the one most widely used for the study of evaporating and combusting droplets. This method usually requires the addition of a fluorophore capable of emitting fluorescent light when illuminated by a laser at an appropriate wavelength. For some organic dyes, like rhodamine B, the intensity of the fluorescence signal can increase or decrease with temperature due to various phenomena such as quenching by solvent molecules, or the variation of the absorption cross-section of the fluorescent molecules with temperature [9]. However, intensity-based fluorescence techniques do not yield absolute quantities and always require a reference [13]. The intensity of the fluorescence signal from a droplet varies with many parameters, such as the droplet 
size, the droplet position with respect to the laser beam and detector, the droplet shape, and the variation of the fluorophore concentration. When the temperature is not the only parameter causing a change in the intensity of the fluorescence signal, the so-called two-colour approach has to be chosen [13. In this approach, the fluorescence signal is detected simultaneously on two emission bands, and the ratio of their intensity allows elimination of the aforementioned parasitic dependencies of the signal.

Two-colour LIF thermometry has been applied successfully in many situations, but its implementation is sometimes quite challenging. One of the challenges relates to the solubility of the fluorophores in the target liquid. Currently, many temperature-sensitive dyes have been reportedly used in liquid solvents such as water and ethanol, but to the best of our knowledge, only pyrromethene 597-8C9 is suitable for measuring temperature in fuel oils. With only one dye, there is a limited choice for the excitation wavelength and the detection bands. More of an issue is that common fuels may contain trace components emitting fluorescence at various wavelengths that may interfere with the dye's emission. Moreover, a recent study by Perrin et al. [14] reveals a strong dependence of pyrromethene 597-8C9 on its chemical environment. A change in chemical composition of the solvent liquid among alkanes significantly alters the fluorescence quenching by the solvent molecules, which results in a change in the temperature sensitivity of pyrromethene 597-8C9. Generally speaking, the dual sensitivity to both temperature and chemical composition is a critical problem when attempting to measure temperature in multi-component mixtures with fluorescent dyes [13]. If the temperature sensitivity is not separated from the variation in the composition of the droplets, errors of tens of ${ }^{\circ} \mathrm{C}$ can be easily made, as pointed out by Perrin et al. [14] in the case of n-dodecane/isohexane droplets evaporating in a high temperature environment. Various authors have also reported a degradation of the fluorescent dye, usually due to a decomposition with temperature [15, 16]. In general, such degradation takes a long time compared to droplet heating and evaporation. This allowed us to perform temperature diagnostics for droplets during their heating and moderate evaporation [12]. During the period of intense evaporation when droplet diameter decreased by about 50\%, however, LIF measurements could be noticeably affected by a fast degradation in rhodamine B. In this case, the application of this approach requires special corrections [12].

On the other hand, phosphors consisting of a host material/matrix doped with deliberately added activator atoms, usually rare earth ions or transi- 
tion metals, are also efficient at emitting luminescence when they are illuminated by a laser source. Some phosphors can be thermographic as they exhibit emission-changing characteristics with temperature. Some comprehensive reviews provide an inventory of thermographic phosphors [17, 18, 19]. They provide useful information regarding the implementation of LIP thermography and properties of the phosphors, such as phosphorescence lifetimes, thresholds of thermal degradations, absorbed and emission spectra 18. Some thermographic phosphors, including BAM:Eu $\left(\mathrm{BaMgAl}_{10} \mathrm{O}_{17}: \mathrm{Eu}^{2+}\right)$ [20, 21, 22, 23], $\mathrm{ZnO}: \mathrm{Ga}$ and $\mathrm{ZnO}: \mathrm{Zn}$ [24], and $\mathrm{La}_{2} \mathrm{O}_{2} \mathrm{~S}: \mathrm{Eu}$ [25], have already been used in liquid flows and in some cases for studying the heating of droplets. The authors of [25] focused on the evaporation of acoustically levitated droplets, using the phosphorescence signal from $\mathrm{La}_{2} \mathrm{O}_{2} \mathrm{~S}$ :Eu. The droplet temperature could be derived from the phosphorescence lifetime using a photomultiplier to record the phosphorescence decline. However, the temperature distribution inside the levitated droplet could not be reconstructed with such an approach.

A high-speed camera could be used to obtain an image of phosphorescence lifetime as demonstrated by Omerane et al. [26]. The decrease in the phosphorescence signal between successive images allows us to determine the value of the phosphorescence lifetime in each pixel. Then, knowing the temperature dependence of the phosphorescence lifetime from prior calibrations, the lifetime can be converted into a temperature. In principle, the method has many advantages, but its application to droplets and sprays is difficult. The low number of phosphor particles inside the droplets and spatial dispersion of the droplets considerably limit the intensity of the phosphorescence signal. Selecting a phosphor with a long lifetime, typically a few ms, is usually required to ease the measurement of the signal decay, but this can be a problem if the droplets are moving fast. In addition, there must be no optical disturbance for a period of the order of the lifetime when the images are acquired. For accurate measurements, the time delay between the images should also be adjusted carefully, which can be an issue when there are large temperature variations in the measurement region.

In [24], the authors investigated the temperature distribution inside methanol droplets burning in the middle of a Bunsen flame. In this study, the droplets were a few millimetres in size and were seeded with $\mathrm{ZnO}: \mathrm{Zn}$ and $\mathrm{ZnO}: \mathrm{Ga}$ particles. Application of LIP thermometry to droplets has great potential for many reasons. Since thermographic phosphors take the form of solid microparticles, their emission is expected to be little influenced by the liquid 
solvent and thus their use is expected to pose fewer difficulties in comparison to LIF fluorophores. They should also be less prone to degradation. Some phosphor particles can resist high temperatures (for instance, BAM:Eu particles can be used above $600^{\circ} \mathrm{C}$ in combustion chambers). Given the long lifetime of phosphorescence, typically in the millisecond range, problems related to undesirable natural fluorescence of trace components in the fuel and scattering of the laser light by the droplets, can be avoided by setting a delay between the laser excitation and signal detection. The size of the phosphor particles, typically in the order of a few $\mu \mathrm{m}$, is sufficiently small to have a thermal response of a few $\mu \mathrm{s} / \mathrm{ms}$, which is sufficient for capturing rapid variations of temperature in most practical situations.

Note that droplet diameters in internal combustion engines (less than 100 $\mu \mathrm{m})$ are much smaller than those considered in our study $(500-1500 \mu \mathrm{m})$. The application of the Laser Induced Phosphorescence (LIP) method to smaller droplets would be difficult due to the large particle diameters required for our analysis $(6-8 \mu \mathrm{m})$.

The current paper is focused on the investigation of applicability of the LIP method to infer the temperature fields in strongly evaporating droplets of several fuels and water. This study will complement our earlier investigation of the temperature field in water droplets using the PLIF method [27].

\section{Experimental setup and measurement technique}

A scheme and a general view of the experimental setup is presented in Figure 1. As in the case of the experiments described in [12], the droplet was introduced into a flow of hot air to investigate its heating and evaporation. The air flow was generated by an air blower (LEISTER CH 6060) achieving air flow velocities up to $5 \mathrm{~m} / \mathrm{s}$. An air heater (LEISTER LE $5000 \mathrm{HT}$ ) was used to control the air temperature in the range $100^{\circ} \mathrm{C}$ to $600^{\circ} \mathrm{C}$. After that, the hot air passed through a cylindrical vertical chamber made of quartz (resistant to heat up to $1800^{\circ} \mathrm{C}$ ), which had inner and outer diameters of 96 $\mathrm{mm}$ and $100 \mathrm{~mm}$, respectively. Four holes with diameters of $10 \mathrm{~mm}$ were drilled in the wall of the chamber. One was used to insert droplets into the chamber, while the others were for optical access.

Note that flows with velocities up to $5 \mathrm{~m} / \mathrm{s}$ around a droplet with radius $1.25 \mathrm{~mm}$ are similar to those with velocities up to $125 \mathrm{~m} / \mathrm{s}$ around a droplet with radius $50 \mu \mathrm{m}$ (typical conditions in internal combustion engines). Droplet intense oscillations were observed when flow velocities exceeded 3.5-4 
$\mathrm{m} / \mathrm{s}$ (see Section 4.5 for the detail) leading to additional errors in the estimation of temperatures in droplets using the LIP method [17, 18, 19]. Thus it was decided not to perform experiments at flow velocities more than 3.5 $\mathrm{m} / \mathrm{s}$.

The droplet was introduced to the hot air chamber with the help of a motorised micromanipulator system with a velocity of $0.05 \mathrm{~m} / \mathrm{s}$. The transfer time was about $1 \mathrm{~s}$, which is quite short in comparison to the time for droplet heating and evaporation in the experiments. Our previous investigations based on the Planar Laser Induced Fluorescence method showed that this time is much shorter compared with the heating up and evaporation times of the droplets under investigation. The latter time for ambient temperatures in the range $100-800^{\circ} \mathrm{C}$ was in the range $13-150 \mathrm{~s}$ [27].

The droplet was suspended on a holder attached to the mobile part of the motorised micromanipulator. This holder consisted of a hollow metal rod made of steel X6CrNiMoTi 17-12-2 with inner and outer diameters equal to $0.3 \mathrm{~mm}$ and $0.6 \mathrm{~mm}$, respectively [12]. The droplets were deposited on the holder with the help of a Finnpipette Novus electronic one-channel dosator. This device allowed us to finely adjust the droplet volume by increments of $0.1 \mu \mathrm{l}$ from $5 \mu \mathrm{l}$ to $30 \mu \mathrm{l}$, which corresponds to an initial droplet radius ranging between $1 \mathrm{~mm}$ and $2 \mathrm{~mm}$.

The errors in the volumes of droplets produced by the disator in our experiments did not exceed $3 \%$, which led to corresponding errors in droplet radii of less than $1 \%$. These errors were less than those which were observed when the droplet radii were inferred from their images, captured with errors of about 1 pixel, and were ignored in our analysis.

BAM:Eu was chosen for temperature measurements due to its high temperature sensitivity in the range $20^{\circ} \mathrm{C}$ to $200^{\circ} \mathrm{C}$. The BAM:Eu particles were dispersed in the fuel liquid immediately before the droplet generation. Mass concentrations of about $3 \mathrm{~g} / \mathrm{l}$ of BAM:Eu particles (radii in the range 6-8 $\mu \mathrm{m})$ were added to all liquid fuels under consideration. The relatively low repetition rate of the laser pulse (10 pulses per second) was a limitation for the frame rate of the video recording. This frame rate, however, was sufficient to establish typical characteristics of heating and evaporation of droplets.

Phosphoresence of BAM:Eu was induced by a pulse Nd:YAG laser equipped with a third harmonic generator (Quantel Q-smart $450 @ 355$ nm, 10 Hz repetition rate, $130 \mathrm{~mJ}$ at maximum energy). The phosphorescence emission of the droplet was separated in the two spectral bands of detection using a dichroic beam splitter. Droplet images were recorded using two highly 
sensitive cameras (M-lite $2 \mathrm{M}$, resolution $1920 \times 1280$ pixel, $10 \mathrm{fps}, 12$ bits). An objective Nikon 200mm f/4 AF-D Macro and an interference filter were mounted in front of each camera to visualise the phosphorescence from the droplet in a specific detection band. As explained in [18, 28], BAM:Eu emission near $450 \mathrm{~nm}$ is more sensitive to temperature than in the region near $420 \mathrm{~nm}$. Therefore, the selected filters were centred around $420 \mathrm{~nm}$ and 455 $\mathrm{nm}$ respectively. Temperature images were recorded following the methodology described in [29]. The droplet was illuminated by a laser sheet along the axis of symmetry (see Figure 1). Recording of the images by the cameras continued until full evaporation of the liquids under consideration. At least 5 experiments were performed for each type of liquid and each ambient temperature that was tested. To determine the temperature field inside the droplet, the images were analysed following the eight steps summarised below, the most important of which are illustrated in Figure 2.

- Step 1: Dark and background noises were removed from each image. This was achieved by recording several images of the registration domain without droplets.

- Step 2: A geometrical correction was applied to the images obtained by the first and second video cameras. This correction was based on a spatial calibration completed during the optical alignment of the system. A calibration target composed of coplanar markers was used (the diameter of the markers was $2 \mathrm{~mm}$, and the distance between them was $3.5 \mathrm{~mm})$.

- Step 3: Each image was compressed, leading to a reduction of the resolution from $1920 \times 1280$ pixels to $960 \times 640$ pixels. This step resulted in softening of the images.

- Step 4: A mask was superimposed on each image to assign a zero value to the pixels outside the droplet. Since the emitted light originated only from the droplet (there were no BAM:Eu particles outside the droplets), a threshold could be easily set by fixing a minimum intensity on the image of the first detection band $(420 \mathrm{~nm})$.

- Step 5: A linear smoothing filter, including an image convolution with elements of $9 \times 9$ pixels, was applied to obtain a more homogeneous distribution of brightness. 
- Step 6: The intensity ratio was calculated via the division, pixel-topixel, of the images of the two cameras. In this ratiometric approach, equivalent to the two-colour method in LIF [13], the intensity ratio is expected to be only a function of liquid temperature.

- Step 7: The image of intensity ratio $\left(R_{1}\right)$ was converted into a distribution of temperatures using the calibration curve (see Figure 3). Thus a two-dimensional temperature distribution could be obtained.

- Step 8: The obtained temperature field was softened using a $5 \times 5$ pixel filter.

When constructing the temperature field, the temperature was always lower on the right hand side of the droplet near the droplet surface as illustrated in Figure 2 (Step 8). This effect was observed whatever the type of liquid and the temperature of the air flow. It is attributed to a saturation of the phosphorescence due to the very high power of the pulse laser excitation, typically in the range of hundreds of $\mathrm{MW} / \mathrm{cm}^{2}$. Above a certain fluence of the laser, phosphorescence looses its proportionality to the energy of the laser pulse and thus the value of the intensity ratio. This effect can be mitigated by a correction to the intensity of the laser sheet on the image, which is basically a flat field correction. A series of 50 droplet images was recorded when the temperature of the air flow was set at $20^{\circ} \mathrm{C}$ (no heat was supplied to the droplet). Each image was analysed following the first 6 steps of the image processing described above. From the average of these 50 images, an intensity ratio $\left(R_{0}\right)$ was calculated. This intensity ratio $R_{0}$ was then used to calculate the normalised ratio $R_{1} / R_{0}$.

\section{Implementation of LIP thermometry in different liquids}

The following liquids were used in our experiments: distilled water ${ }^{1}$, referred to as WA; aviation kerosene TC-1 ${ }^{2}$, referred to as KE; gasoline with Octane number 95 (petroleum oil), referred to as PO; and Diesel fuel (Ultralow-sulfur Diesel - ULSD), referred to as DI. The thermophysical character-

\footnotetext{
${ }^{1}$ In Russia, its standard is classified as GOST 6709-72

${ }^{2}$ European analogue of Jet-A1 fuel
} 


\begin{tabular}{|c||c|c|c|c|c|c|c|c|}
\hline Liquid & $C$ & $Q_{e}$ & $k$ & $\nu$ & $\rho$ & $\sigma$ & $\alpha$ & $T_{b}$ \\
\hline \hline WA & 4182 & 2.26 & 0.6062 & 1.006 & 1000 & 73 & 0.143 & 100 \\
\hline DI & 2010 & 0.25 & 0.117 & 8.94 & 878 & 31 & 0.067 & $320-360$ \\
\hline KE & 2220 & 0.23 & 0.115 & 1.819 & 819 & 27 & 0.07 & $150-250$ \\
\hline PO & 2090 & 0.31 & 0.112 & 0.65 & 751 & 22 & 0.072 & $185-205$ \\
\hline \hline
\end{tabular}

Table 1: Thermophysical characteristics of liquids (water (WA), Diesel fuel (DI), kerosene $(\mathrm{KE})$ and petroleum oil (PO)) at temperature $20^{\circ} \mathrm{C}$ and atmospheric pressure 30. $C$ stands for specific heat capacity in $\mathrm{J} /(\mathrm{kg} \mathrm{K}), Q_{e}$ stands for specific heat of evaporation in $\mathrm{MJ} / \mathrm{kg}, k$ stands for thermal conductivity in $\mathrm{W} /(\mathrm{m} \mathrm{K}), \nu$ stands for kinematic viscosity in $\mathrm{mm}^{2} / \mathrm{s}, \rho$ stands for density in $\mathrm{kg} / \mathrm{m}^{3}, \sigma$ stands for surface tension in $\mathrm{mN} / \mathrm{m}, \alpha$ stands for thermal diffusivity in $\mathrm{mm}^{2} / \mathrm{s}, T_{b}$ stands for boiling temperature in ${ }^{\circ} \mathrm{C}$.

\begin{tabular}{|c||c|c|c|c|}
\hline Liquid & Wavelength $(\mathrm{nm})$ & $n$ & $\zeta$ in $1 / \mathrm{m}$ & $\kappa$ in $1 / \mathrm{m}$ \\
\hline \hline WA & 355 & 1.348 & 0.0013 & 0.1 \\
\hline WA & 420 & 1.340 & 0.0011 & 0.0105 \\
\hline WA & 455 & 1.339 & 0.00106 & 0.0095 \\
\hline \hline
\end{tabular}

Table 2: Refractive index $(n)$, scattering coefficient $(\zeta)$ and absorption coefficient $(\kappa)$ for water at three wavelengths [31].

istics of these liquids and optical characteristics of water are summarised in Tables 1 and 2, respectively.

Since the thermophysical parameters (e.g. density, viscosity, surface tension) of fuels are different from those of distilled water, fuel droplet generation had to be preceded by the calibration of the dosimeter. Without calibration, the volumes of the generated fuel droplets were slightly larger than those of distilled water. During the calibration process, the generated fuel droplets were weighed using a Vibra HT 84RCE micro-scale (in $10^{-5} \mathrm{~g}$ steps). Fuel droplet volumes were inferred from their weights and densities. Varying the volumes of droplets produced by the dosator in $0.1 \mu \mathrm{l}$ steps we were able to match the volumes of fuel droplets to those of distilled water. This approach allowed us to generate fuel droplets with volumes almost identical to those of distilled water with errors not exceeding $0.07 \mu$ l.

In order to select a liquid suitable for measurement, the following two conditions must be met. Firstly, the phosphor particles have to be easily dispersed into the liquid. Secondly, the liquid has to be transparent (i.e. it 
must have low scattering and absorption coefficients) at the laser wavelength (355 nm) and the wavelengths of BAM:Eu emission (420/455 nm). To check this second condition, it is necessary to characterise the absorption coefficient $\kappa$ in the Bouguer-Beer law:

$$
I=I_{0} \exp (-\kappa x)
$$

where $x$ is distance, $I / I_{0}$ is the attenuation of light intensity after it has passed distance $x$. As follows from Table 2, the scattering coefficient is about an order of magnitude less than the absorption coefficient, which allows us to ignore the effect of scattering at this stage. Using Eq.(1), $I / I_{0}$ can be estimated based on a distance $x$ equal to two droplet radii $\left(2 R_{d}\right)$ to assess (1) the absorption of the laser at wavelength $355 \mathrm{~nm},(2)$ the absorption of BAM:Eu emission at $420 \mathrm{~nm}$ and $455 \mathrm{~nm}$. As follows from these estimates, the maximal losses due to absorption at $355 \mathrm{~nm}, 420 \mathrm{~nm}$ and $455 \mathrm{~nm}$ are $0.03 \%, 0.0331 \%$ and $0.00328 \%$, respectively. This is small enough to neglect the effect of laser absorption and phosphorescence light re-absorption within the droplet.

To determine the temperature field (Step 7 of the reconstruction), a calibration curve is required for each liquid. For that, the ratio of the phosphorence intensities at $420 \mathrm{~nm}$ and $455 \mathrm{~nm}\left(R_{1}\right)$ was calculated in the central part of the droplet (more precisely a region of about $30 \%$ of the total crosssectional area). Then, following [24], $R_{1}$ was averaged at each time instant of the droplet heating. Figure 3a shows the evolution of $R_{1}$ for the four liquids as a function of the droplet temperature $T_{d}(t)$, which was measured separately using a thermocouple embedded in the droplet under exactly the same conditions (type of liquid, temperature and velocity of the flow, droplet radius) as for the LIP measurements. An S-type thermocouple (platinumplatinum/Rhodium, seal diameter $0.05 \mathrm{~mm}$, inertia $0.1 \mathrm{~s}$ and errors $\pm 1^{\circ} \mathrm{C}$ ) was positioned at the centre of the droplet. Using an analogue input module (National Instruments 9219), $T_{d}$ was recorded every $0.5 \mathrm{~s}$ until complete droplet evaporation. As can be seen in Figure 3a, the intensity ratio $R_{1}$ differs considerably between the liquids.

In Figure 3b, the evolution of $R_{1}$ normalised by its counterpart at $20^{\circ} \mathrm{C}$ $\left(R_{0}\right)$ is presented as a function of the temperature for the same liquids as shown in Figure 3a. As can be seen, the normalised ratio $R_{1} / R_{0}$ is most sensitive to temperature for kerosene. There is no obvious explanation for such a difference. The choice of experimental parameters (including initial 
droplet sizes, air velocities, laser power, and heating rate) allows us to exclude a significant contribution from the adverse effects discussed in the following section. It was noticed that the scattering of the experimental data differed considerably between the four liquids. For DI and PO fuels, data scattering for $R_{1}$ was typically $5 \%$ and $10 \%$, while it did not exceed $2-3 \%$ for WA and KE. The functional dependence of $R_{1}$ versus $T_{d}$ was approximated by a second order polynomial and used for converting the intensity ratio into temperature in Step 7.

\section{Limitations of the LIP method and corrections to the results}

When the technique described above was applied to droplet measurements, a number of issues emerged. In what follows, these issues are presented, together with our efforts to mitigate them. The reliability of LIP measurements is assessed.

\subsection{Concentration of BAM:Eu particles in the liquid}

Several tests were carried out in order to determine the effects of the mass concentration $\gamma$ of phosphor particles. For $6 \mathrm{~g} / \mathrm{l}<\gamma<10 \mathrm{~g} / \mathrm{l} \mathrm{g} / \mathrm{l}$ the temperature field was sometimes not homogeneous. For $10 \mathrm{~g} / \mathrm{l}<\gamma<15$ $\mathrm{g} / \mathrm{l}$, the inhomogeneities become predominant. For $\gamma>15 \mathrm{~g} / \mathrm{l}$, it was practically impossible to reconstruct the temperature field from the experiments. For even larger values of $\gamma$, particles could be agglomerated, leading to the formation of zones with high particle concentrations. This was observed to yield predictions of unphysically low or high liquid temperatures, as shown in Figure 4. On the other hand, for low values of $\gamma$, there were not enough particles to fill the whole droplet volume. As a result, numerous 'blind zones' remain, where the temperature could not be estimated.

From these preliminary tests, a low concentration of $\gamma$ (ranging between $3 \mathrm{~g} / \mathrm{l}$ and $4 \mathrm{~g} / \mathrm{l}$ ) was selected for the experiments, but obviously the evaporation induces an increase in the concentration of phosphor particles. As an example, a four times reduction in the droplet volume leads to $\gamma=12 \mathrm{~g} / \mathrm{l}$, for which unacceptable inhomogeneities in the predicted temperature field can be observed.

The effect of the concentration in phosphor particles is intriguing. At this stage, only some tentative explanations can be proposed: the transfer of energy between the particles when they are agglomerated; wavelengthdependent multiple scattering of the phosphorescence by the particles; a 
supplementary phosphorescence induced by reabsorption... It would not be easy to find the correct explanation and this would certainly require the design of special experiments which are beyond the scope of this paper. In a pragmatic way, the focus of our investigation was limited to finding the range of $\gamma$ for which the temperature field can be found with confidence.

\subsection{Distribution of BAM:Eu particles in the droplet}

A homogeneous distribution of BAM:Eu particles inside the droplet is required to also obtain a smooth temperature field inside the droplet. This can be achieved with the help of liquid recirculation inside the droplet driven by natural and/or forced convection. In the absence of recirculation, BAM:Eu particles tend to deposit at the bottom of the droplet in about 20-30 s, which can lead to the formation of agglomerates. In our case, thanks to the air flow and the gradients of air temperature outside the droplet, the stirring of the suspension during the experiment was constant [32].

Reasonably homogeneous distribution of BAM:Eu particles inside the droplet can be achieved when ambient air velocity exceeded $3 \mathrm{~m} / \mathrm{s}$. In this case, the velocities of liquid recirculating inside the droplet were in the range $1.5-2 \mathrm{~mm} / \mathrm{s}$ [32]. In the case of high liquid recirculation velocities (more than $4 \mathrm{~mm} / \mathrm{s}$ ) a Hill vortex is formed and the particles tended to agglomerate near the centre of the droplet and at its periphery. Note that this tendency was not observed in our earlier experiments, described in [32], where titanium dioxide particles, with radii less that $1 \mu \mathrm{m}$ were used instead of BAM:Eu particles with radii in the range $6-8 \mu \mathrm{m}$. Hence, it is essential to control the liquid recirculation velocities. Using Particle Image Velocimetry (PIV) in combination with LIP allowed us to evaluate particle displacements in the liquid droplet at various stages of droplet heating and evaporation. This was particularly important in the case of highly viscous liquids and high concentrations of solid particles [17].

\subsection{Heating rate}

The analysis of our experimental data revealed that LIP measurements can be affected by the rate of droplet heating $\left(W_{h}\right)$. This unexpected effect makes it difficult to obtain reliable temperature measurements. Tests were conducted to identify when the average temperature measured by LIP differed from the one inferred from a thermocouple by more than $10 \%$. It was established that LIP measurements were reliable only for $W_{h}$ lower than 
$25^{\circ} \mathrm{C} / \mathrm{s}$ (Figure $5 \mathrm{~b}$ ). For a given air temperature $T_{a}$, the heating rate $W_{h}$ of the droplet increased with the boiling temperature of the liquid $T_{b}$. This is illustrated in Figure 5a where the value of $W_{h}$ inferred from thermocouple measurements is plotted as a function of the minimal value of the boiling temperatures taken from Table 1. Using the results presented in Figure 5a and $\mathrm{b}$, reliable measurements with LIP can be provided for the whole range of air temperatures (up to $500^{\circ} \mathrm{C}$ ) only for water (WA). For kerosene (KE), $T_{a}$ must not exceed $400^{\circ} \mathrm{C}$, while the upper limit is $300^{\circ} \mathrm{C}$ for Diesel fuel (DI) and petroleum oil (PO).

We believe that the effect of heating on the quality of our measurements is likely to be attributed to rapid growth of droplet temperatures and droplet evaporation associated with high heating rates. This evaporation is expected to lead to preferential accumulation of particles near the surface of the droplet. Assuming that the diffusion coefficient of particles in liquid is close to that of n-dodecane, we obtain that $D_{l}=2.73 \times 10^{-9} \mathrm{~m}^{2} / \mathrm{s}$ at $T=298$ $\mathrm{K}$ [33]. Thus for droplets with initial radius $R_{d}=1.25 \mathrm{~mm}$ we obtain the characteristic diffusion time of these particles inside droplets $R_{d}^{2} / D_{l} \approx 572 \mathrm{~s}$. This is much longer than the characteristic time of the processes under consideration (10 s), and we can ignore the diffusion of particles from the surface of the droplets to their centre altogether (see 34] for the details). Remembering that $D_{l}$ is proportional to temperature in $\mathrm{K}$ [35], we can expect that the characteristic diffusion time becomes equal to $286 \mathrm{~s}$ when the temperature doubles. Even in this case, however, this time would be much longer than 10 s. Also, the increased heating rate might lead to intensification of convective flows inside the droplet due to reduction of liquid viscosity with increase in temperature and Soret effects due to the formation of temperature gradients inside droplets. These effects, however, are not expected to be strong.

\subsection{Laser power}

A collimator based on optical lenses was used to transform the cylindrical laser beam at the output of the laser into a flat laser sheet. This optical system allowed us to vary the laser energy flux reaching the droplet in the range $0.2-2.33 \mathrm{~mJ} / \mathrm{mm}^{2}$ and thus to test the effect of laser power on LIP measurements.

For a given BAM:Eu particle concentration and a given laser power, signal intensity is not the same for the different liquids. For example, at about $30 \%$ of the maximum laser energy, the grey levels of the camera detecting the signal in the band $455 \mathrm{~nm}$ were 1400-2000 counts for WA, 2600-3700 counts 
for KE, 3100-4000 counts for DI and 3200-4096 counts for PO, respectively. In the case of DI and PO, an increase in concentration of BAM:Eu particles, which inherently occurs due to droplet evaporation and particle agglomeration, can easily lead to a saturation of the grey levels in the images since the limit is 4096 count for our 12 bit camera. When this happens, the reconstruction of a reliable temperature field is not possible (Figure 6).

On the other hand, the intensity of the phosphorescence signal was not sufficient to perform reliable measurements when the laser energy flux was lower than $0.27 \mathrm{~mJ} / \mathrm{mm}^{2}$. Under these conditions, the $420 / 455 \mathrm{~nm}$ ratios appeared less sensitive to temperature change. It is believed that in this case laser energy does not lead to strong enough absorption and emission by BAM:Eu particles.

From the above discussion, the laser energy should be selected very carefully. In the present study, the laser fluence was fixed around $0.47 \mathrm{~mJ} / \mathrm{mm}^{2}$ in the experiments with the different liquids. This is large enough to induce a significant phosphorescence of BAM:Eu particles, but small enough to avoid reaching the maximal grey-level value of 4096 .

\subsection{Droplet shape oscillations}

Oscillations in the droplet shape, when they are placed in the air flow, can lead to significant variations in the signal level in the images. The effect of these oscillations could not be completely eliminated by taking into consideration the intensity ratio, as can normally be expected in the 2-colour method. As shown in Figure 7, droplet oscillations induce variations in the average temperature of $3-7^{\circ} \mathrm{C}$ in the case of a kerosene droplet. The relevant distributions of temperature, obtained using the LIP method, are shown in the same figure. Note that a change in the droplet shape modifies the laser energy distribution in the droplet, and thus the saturation of phosphorescence within it. Hence, the effect of droplet shape might be related to the fact that phosphorescence is partially saturated in our experiments, but we cannot provide quantitative verification of this due to the obvious difficulty of performing measurements at very low laser powers.

\subsection{Averaging of the temperature maps}

Despite our attempts to avoid droplet oscillations, to select the right laser power, air velocity and particle concentrations, spatial fluctuations in the temperature field were sometimes still observed (Case \#1 in Figure 8). To overcome this problem, a smoothing of the temperature was performed 
based on a sliding average over time. The temperature at each point in space was calculated based on the averaging of the temperatures obtained for the previous, current and the following frames. The results shown as Case \#2 in Figure 8 were compared with thermocouple measurements. For that comparison, only the central areas of the droplets were considered, since the thermocouple was also located within this area. The averaging gives acceptable results, but it tends to slightly reduce the actual values of the temperatures for a rapidly heated droplet. The discrepancy was typically $2-4^{\circ} \mathrm{C}$ (as in the example presented in Figure 8), but could reach $5-20^{\circ} \mathrm{C}$ in the case of intense heating at high gas temperatures. Therefore, this averaging procedure was only applied when the heating rate of the droplet was moderate.

\section{Temperature fields inside the droplets}

Figure 9 illustrates the time evolution of the temperature distribution inside a kerosene droplet heated in the air flow at different temperatures ranging from $100^{\circ} \mathrm{C}$ to $500^{\circ} \mathrm{C}$. For these measurements, all recommendations discussed above were taken into account. In the initial stage of the droplet lifetime, the fuel is strongly heated and the temperature distribution is rather inhomogeneous inside the droplet. Heating is initially faster in the upper part of the droplet, which is in the vicinity of the holder. Temperature differences inside the droplet reached $25-30^{\circ} \mathrm{C}$ (for $T_{a} \approx 100^{\circ} \mathrm{C}$ ), $30-35^{\circ} \mathrm{C}$ (for $\left.T_{a} \approx 200^{\circ} \mathrm{C}\right), 40-45^{\circ} \mathrm{C}\left(\right.$ for $T_{a} \approx 300^{\circ} \mathrm{C}$ ), $45-50^{\circ} \mathrm{C}$ (for $\left.T_{a} \approx 400^{\circ} \mathrm{C}\right), 50-55^{\circ} \mathrm{C}$ (for $T_{a} \approx 500^{\circ} \mathrm{C}$ ). When the effects of evaporation start to play a significant role (a strong reduction in droplet size can be seen after a few seconds), the temperature field becomes progressively more homogeneous. The liquid temperatures continue to grow at a slower pace and finally approach to asymptotic values for $T_{a} \leq 300^{\circ} \mathrm{C}$. These asymptotic values are $80^{\circ} \mathrm{C}$ (for $T_{a} \approx 100^{\circ} \mathrm{C}$ ), $110^{\circ} \mathrm{C}\left(\right.$ for $T_{a} \approx 200^{\circ} \mathrm{C}$ ), and $130^{\circ} \mathrm{C}$ (for $T_{a} \approx 300^{\circ} \mathrm{C}$ ). For $T_{a}>300^{\circ} \mathrm{C}$ temperatures inside droplets continue to grow until their complete evaporation.

\section{Modelling versus experimental data}

In this section, the experimental results presented in the previous sections are investigated using the Effective Thermal Conductivity/Effective Diffusivity (ETC/ED) model (see [2, 3] for a detailed description of this model). One 
of the key limitations of this model is that in the case of droplets in an air flow it can be applied to predict droplet radii and average surface temperatures/compositions, but not the distributions of temperatures/compositions inside droplets. In some papers, including [27], it has been used to investigate temperature distribution inside droplets in an air flow. These predictions of the model are expected to show the correct trends of temperature distribution, but not the details of this distribution.

As in the case of most previous studies of the process, we assume that droplets are spherical and the effects of the droplet support will be ignored. A new simplified model taking into account the effects of this support on droplet heating and evaporation was suggested and developed in [27]. In this and the following paper [36], where this model was used, it was shown that this effect is relatively small. The errors introduced by these assumptions are generally lower than the errors of experimental measurements.

These assumptions allow us to apply the version of ANSYS Fluent which incorporates the ETC/ED model for the analysis of the experimental results. This version of ANSYS Fluent is described in [37, 38]. The model implemented in this software is based on the analytical solutions to the heat conduction and species diffusion equations in the liquid phase. The model described in [37] is based on the analytical solutions to the heat conduction equation and was applied to mono-component droplets. In [38] this model was generalised to take into account both analytical solutions to the heat conduction and species diffusion equations. In both cases, the model was incorporated into this software via User-Defined Functions (UDF).

To simplify the problem further, we ignore the multi-component compositions of kerosene, Diesel fuel and gasoline fuel and approximate them as n-decane $\left(\mathrm{C}_{10} \mathrm{H}_{22}\right)$, n-dodecane $\left(\mathrm{C}_{12} \mathrm{H}_{26}\right)$ and iso-octane $\left(\mathrm{C}_{8} \mathrm{H}_{18}\right)$, respectively. These components are the dominant ones in the corresponding multicomponent fuels. In this case, only the ETC model was used in our analysis. The effect of the actual composition of these fuels on droplet heating and evaporation is discussed in [36, 39, 40].

The analytical solution to the heat conduction equation was presented in the form of an infinite series each term of which was a function of a specific eigenvalue $\lambda_{n}(n=1,2,3, \ldots \ldots)$. This solution was incorporated in the numerical code at each time step. When performing calculations fifty terms in this series were used; we observed no difference in the results when this number of terms was increased. Time steps $10^{-3} \mathrm{~s}$ were used in calculations; 100 cells along the droplet radius were used to calculate integrals for the 
parameters used in the above-mentioned series. The roots of the equation for $\lambda_{n}$ were found using the bisection method with absolute accuracy of $10^{-6}$.

The droplet initial temperatures in our calculations were assumed equal to $300 \mathrm{~K}\left(27^{\circ} \mathrm{C}\right)$. Based on our experimental measurements using thermocouples, the initial droplet temperatures in all cases could be slightly more than this value and could reach up to $33^{\circ} \mathrm{C}$. This possible slight increase in the droplet initial temperatures would have led to very minor modification of our results without affecting our conclusions. The droplets were introduced into the air flow over $1.25 \pm 0.1 \mathrm{~s}$. This time is the period between the introduction of the droplets into the cylinder and the first measurements. This time was identified with the time instants when droplet heating started.

The plots of droplet surface temperature $T_{s}$ versus time for water, ndecane $\left(\mathrm{C}_{10} \mathrm{H}_{22}\right)$, n-dodecane $\left(\mathrm{C}_{12} \mathrm{H}_{26}\right)$ and iso-octane $\left(\mathrm{C}_{8} \mathrm{H}_{18}\right)$ (approximations of kerosene, Diesel fuel and gasoline fuel) droplets, predicted by the Effective Thermal Conductivity (ETC) and Infinite Thermal Conductivity (ITC) (thermal conductivities of droplets are assumed to be large) models, assuming that ambient air temperature and velocity are equal to $300^{\circ} \mathrm{C}$ and $3 \mathrm{~m} / \mathrm{s}$, respectively, are shown in Figure 10. The experimentally observed values of $T_{s}$ are shown in the same figures. The initial droplet radii for water, kerosene, Diesel fuel and gasoline fuel droplets, observed experimentally and used in modelling, were $1.54 \pm 0.024 \mathrm{~mm}, 1.16 \pm 0.024 \mathrm{~mm}, 1.175 \pm 0.024 \mathrm{~mm}$ and $1.12 \pm 0.024 \mathrm{~mm}$, respectively. The time step used in all calculations was $1 \mathrm{~ms}$.

The experimental points shown in Figure 10 (empty circles) refer to single droplets. At any time instant, however, the temperatures were measured at seven different points at the droplet surface. Since droplet heating was inhomogeneous, temperatures at these points could differ substantially one from another (up to $15-20^{\circ} \mathrm{C}$, cf. Figure 9). Inhomogeneity of BAM:Eu particles near droplet surfaces might also contribute to inhomogeneity of the measured temperature distribution. Our comparison between modelling and experimental results was focused not on individual measurements at seven points at the droplet surface but on the average temperatures in the nearsurface regions of droplets (filled stars in Figure 10).

The thermodynamic and transport properties of water, n-decane $\left(\mathrm{C}_{10} \mathrm{H}_{22}\right)$, n-dodecane $\left(\mathrm{C}_{12} \mathrm{H}_{26}\right)$ and iso-octane $\left(\mathrm{C}_{8} \mathrm{H}_{18}\right)$, were taken from [41], [36], [42] and [43], respectively.

As follows from Figure 10, in all cases at the initial stage of droplet heating the ETC model predicts higher droplet temperatures than those predicted 
by the ITC model. This result is expected as in this case heat supplied to the droplet surface is spent only on heating the near surface area of the droplet in the ETC model, while in the ITC model it is spent on heating the whole droplet.

Also, it follows from the same figure that the agreement between modelling and experimental results is rather poor in all cases although the model predicts correct trends in the evolution of droplet surface temperatures. This could be attributed to both the limitations of the model used for the analysis and the uncertainty of the experimental data. The latter is particularly visible in the case of water droplets (see Figure 10a). Note that the application of the ETC model instead of the ITC model does not lead to better agreement with experimental data.

The errors in the LIP measurements increased from $4.9^{\circ} \mathrm{C}$ to $7.8^{\circ} \mathrm{C}$ when droplet temperatures increased from $20^{\circ} \mathrm{C}$ to $90^{\circ} \mathrm{C}$ [17. The main contributors to the errors in temperature measurements comes are the inhomogeneity of surface temperature observed in the experiments (the ETC model predicts only the average surface temperature), non-sphericity of observed droplets, and droplet oscillations described earlier in the paper. Also, the experimental data refer to the region below the droplet surface where the temperatures are slightly lower that those at the droplet surface, which are the temperatures actually predicted by the model. In the experiments, the area in the immediate vicinity of the droplet surface is considered to be the dead zone.

There were at least two main causes of errors in the predictions of the model. These were errors related to the assumptions of the model (e.g. assumption that droplets are spherical) and errors in determining the input parameters. It would be difficult for us to estimate the first group of errors, so we will focus only on the second. The maximal errors in determining ambient air temperatures and flow velocities were $\pm 7 \mathrm{~K}$ and $\pm 0.5 \mathrm{~m} / \mathrm{s}$, respectively. These errors led to errors of about $\pm 1 \mathrm{~K}$ in predicting the droplet surface temperatures. Even larger errors in predicting this temperature could have been caused by our assumption that the mass fractions of water and fuel in ambient air are zero. It would not be easy for us to estimate precise values of these mass fractions. Bearing in mind these modelling and experimental errors, it may not be possible to obtain better agreement between modelled and experimental results than those shown in in Figure 10. 


\section{Conclusions}

The temperature fields in droplets of four widely used liquids (water, kerosene, Diesel and gasoline (petroleum oil) fuels), obtained using the method of Laser Induced Phosphorescence (LIP), are presented. In this method, phosphor is introduced into the droplets for the emission of laser light. The droplets, with initial radii in the range 1 to $2 \mathrm{~mm}$, were heated in air at temperatures in the range $20^{\circ} \mathrm{C}$ to $500^{\circ} \mathrm{C}$, and subject to air flow velocities in the range $3-3.5 \mathrm{~m} / \mathrm{s}$. The range of applicability and advantages/shortcomings of the method are established alongside the sources of errors.

It is pointed out that the method cannot be applied when the concentration of phosphor particles is too large $(\gamma>15 \mathrm{~g} / \mathrm{l})$ or too small $(\gamma<1)$ $\mathrm{g} / \mathrm{l}$. In the first case, the inhomogeneities of the particle distribution become predominant, leading to their agglomeration. In the second case, there may not be enough particles to fill the whole droplet volume, leading to the formation of 'blind zones', where the temperature cannot be estimated. The concentration $\gamma=3-4 \mathrm{~g} / \mathrm{l}$ was selected for the experiments.

The analysis of the experimental data showed that LIP measurements can be affected by the rate of droplet heating. It was shown that no reliable LIP measurements were possible for heating rates greater than $60^{\circ} \mathrm{C} / \mathrm{s}$. A threshold of laser energy flux, $0.27 \mathrm{~mJ} / \mathrm{mm}^{2}$, below which the ratios of intensities at $420 \mathrm{~nm}$ and $455 \mathrm{~nm}$ were not sensitive to temperature changes, was established experimentally. The energy flux of around $0.47 \mathrm{~mJ} / \mathrm{mm}^{2}$ was chosen to ensure that it was large enough to trigger phosphorescence of BAM:Eu particles, but small enough to prevent the brightness reaching its maximal value. It was shown that droplet oscillations induce a variation in droplet temperatures. To mitigate this effect, the temperature at each point in space was estimated based on the averaging of its values obtained for the previous, current and the following frames.

The experimentally observed droplet surface temperatures are compared with the predictions of the customised version of ANSYS Fluent with the Effective Thermal Conductivity (ETC) model incorporated into it via User Defined Functions (UDF). It is shown that ANSYS Fluent can correctly predict the trend of the time evolution of these temperatures.

\section{Acknowledgements}

Work on this paper was supported by the National Research Tomsk Polytechnic University (project VIU-ISHFVP-60/2019) (contributions by P.A. 
Strizhak and R.S. Volkov), a Scholarship from the President of the Russian Federation (MN-2.4/3052) (contribution by D.V. Antonov), the EPSRC, UK (Grant no. EP/M002608/1) and the Royal Society (UK) (Grant no. IEC 192007) (contribution by S.S. Sazhin).

Mr. D Antonov is grateful to Dr. O. Rybdylova for instructing him regarding the details of ANSYS Fluent code and writing new UDFs for this paper. Our special thanks are to Ms. A. Pinheiro for sharing kerosene properties and performing preliminary simulations to confirm the results presented in Figure 10. Professor F. Lemoione, Dr. O. Rybdylova and Ms. A. Pinheiro are gratefully acknowledged for very helpful and constructive comments on the draft version of the paper. 


\section{References}

[1] A.Y. Varaksin, Fluid dynamics and thermal physics of two-phase flows: Problems and achievements, High Temperature 51 (2013) 377-407.

[2] S.S. Sazhin, Droplets and Sprays. Springer (2014).

[3] S.S. Sazhin, Modelling of fuel droplet heating and evaporation: Recent results and unsolved problems, Fuel 196 (2017) 69-101.

[4] D.O. Glushkov, S.V. Syrodoy, A.V. Zakharevich, P.A. Strizhak, Ignition of promising coal-water slurry containing petrochemicals: Analysis of key aspects, Fuel Proc. Technol. 148 (2016) 224-235.

[5] O.P. Korobeinichev, A.G. Shmakov, V.M. Shvartsberg, A.A. Chernov, S.A. Yakimov, K.P. Koutsenogii, V.I. Makarov, Fire suppression by lowvolatile chemically active fire suppressants using aerosol technology, Fire Safety J. 51 (2012) 102-109.

[6] S. Chen, P. Bartello, M.K. Yau, P.A. Vaillancourt, K. Zwijsen, Cloud droplet collisions in turbulent environment: Collision statistics and parameterization, J. Atmos. Sci. 73(2) (2016) 621-636.

[7] H. Kan, H. Nakamura, S. Watano, Effect of collision angle on particleparticle adhesion of colliding particles through liquid droplet, Adv. Powder Technol. 29(6) (2018) 1317-1322.

[8] S.Y. Misyura, Contact angle and droplet heat transfer during evaporation on structured and smooth surfaces of heated wall, Applied Surface Science 414 (2017) 188-196.

[9] W. Chaze, O. Caballina, G. Castanet, F. Lemoine, Spatially and temporally resolved measurements of the temperature inside droplets impinging on a hot solid surface, Experiments in Fluids 58(8)(2017) article id. 96, 16 pp.

[10] M.Y. Khan, Z.A. Abdul Karim, A. Rashid A. Aziz, M.R. Heikal, C. Crua, Puffing and microexplosion behavior of water in pure diesel emulsion droplets during Leidenfrost effect, Combust. Sci. Technol. 189 (2017) 1186-1197. 
[11] C. Cen, H. Wu, C. Lee, L. Fan, F. Liu, Experimental investigation on the sputtering and micro-explosion of emulsion fuel droplets during impact on a heated surface, Int. J. Heat Mass Transfer 132 (2019) 130137.

[12] R.S. Volkov, P.A. Strizhak, Measuring the temperature of a rapidly evaporating water droplet by Planar Laser Induced Fluorescence, Measurement 135 (2019) 231-243.

[13] F. Lemoine, G. Castanet, Temperature and chemical composition of droplets by optical measurement techniques: a state-of-the-art review, Experiments in Fluids 54(7)(2013) article id. 1572, 34 pp.

[14] Lionel Perrin, Guillaume Castanet, Fabrice Lemoine, Characterization of the evaporation of interacting droplets using combined optical techniques, Experiments in Fluids 56 (2015) article id. 29, 16 pp.

[15] W. Chaze, O. Caballina, G. Castanet and F. Lemoine, The saturation of the fluorescence and its consequences for laser-induced fluorescence thermometry in liquid flows, Experiments in Fluids 57:58 (2016) article id. 58,18 pp.

[16] J. Sakakibara, R. J. Adrian, Whole field measurement of temperature in water using two-color laser induced fluorescence, Experiments in Fluids 26(1/2)(1999) 7-15. 135 (2019) 231-243.

[17] C. Abram, B. Fond, F. Beyrau, Temperature measurement techniques for gas and liquid flows using thermographic phosphor tracer particles, Progress in Energy and Combustion Science 64 (2018) 93-156.

[18] J. Lindén, Laser Induced Phosphor Thermometry - Feasibility and precision in combustion applications. Lund University (2012).

[19] R. Hasegawa, I. Sakata, H. Yanagihara, B. Johansson, A. Omrane, M. Aldén, Two-dimensional gas-phase temperature measurements using phosphor thermometry, Appl. Phys. B 88 (2007) 291-296.

[20] C. Abram, B. Fond, A.L. Heyes, F. Beyrau, High-speed planar thermometry and velocimetry using thermographic phosphor particles, Applied Physics B 111(2) (2013) 155-160. 
[21] A. Charogiannis, F. Beyrau. Laser induced phosphorescence imaging for the investigation of evaporating liquid flows, Experiments in Fluids 54 (2013) article id. 1518, 15 pp.

[22] D. Witkowski, D.A. Rothamer, Investigation of aerosol phosphor thermometry (APT) measurement biases for Eu:BAM, Appl. Phys. B 124 (2018) 202 (2018).

[23] A.O. Ojo, B. Fond, C. Abram, B.G.M. Van Wachem, A.L. Heyes, F. Beyrau, Thermographic laser Doppler velocimetry using the phaseshifted luminescence of $\mathrm{BAM}: \mathrm{Eu}^{2+}$ phosphor particles for thermometry, Opt. Express. 25 (10) (2017) 11833-11843.

[24] G. Särner, M. Richter, M. Aldén, Two-dimensional thermometry using temperature-induced line shifts of $\mathrm{ZnO}: \mathrm{Zn}$ and $\mathrm{ZnO}: \mathrm{Ga}$ fluorescence, Opt. Lett. 33 (2008) 1327-1329.

[25] A. Omrane, S. Santesson, M. Aldéna, S. Nilsson, Laser techniques in acoustically levitated micro droplets, Lab on a Chip 4 (2004) 287-291.

[26] A. Omrane, G. Särner, M. Aldén, 2D-temperature imaging of single droplets and sprays using thermographic phosphors, Applied Physics B: Lasers and Optics 79 (2004) 431434.

[27] P.A. Strizhak, R.S. Volkov, G. Castanet, F. Lemoine, O. Rybdylova, S.S. Sazhin, Heating and evaporation of suspended water droplets: Experimental studies and modelling, Int. J. Heat Mass Transfer 127 (2018) 92-106.

[28] J. Lindén, N. Takada, B. Johansson, M. Richter, M. Aldén, Investigation of potential laser-induced heating effects when using thermographic phosphors for gas-phase thermometry, Applied Physics B. 96 (2009) 237240.

[29] R.S. Volkov, G.V. Kuznetsov. P.A. Strizhak, Temperature and velocity fields of the gas-vapor flow near evaporating water droplets, International Journal of Thermal Sciences 134 (2018) 337-354.

[30] N.B. Vagraftik, Handbook of Thermophysical Properties of Fluids. Stars Publishing House, Moscow (2006) (in Russian). 
[31] A.A. Rogov, Taking Photoes in Water, Nauka Publishing House, Moscow (1964) (in Russian).

[32] R.S. Volkov, P.A. Strizhak, Research of temperature fields and convection velocities in evaporating water droplets using Planar Laser-Induced Fluorescence and Particle Image Velocimetry, Experimental Thermal and Fluid Science 97 (2018) 392-407.

[33] B.E. Poling, J.M. Prausnitz, J.P. OConnell, The Properties of Gases and Liquids, Fifth Edition, 2001.

[34] S.S. Sazhin, O. Rybdylova, A.S. Pannala, S. Somavarapu, S.K. Zaripov, S.K. A new model for a drying droplet, International Journal of Heat and Mass Transfer 122 (2018) 451-458.

[35] R.B. Bird, E.W. Stewart, E.N. Lightfoot, Transport Phenomena, second ed., Wiley \& Sons, New York, Chichester, 2002.

[36] L. Poulton, O. Rybdylova, I.A. Zubrilin, S.G. Matveev, N.I. Gurakov, M. Al Qubeissi, N. Al-Esawi, T. Khan, V.M. Gun'ko, S.S. Sazhin, Modelling of multi-component kerosene and surrogate fuel droplet heating and evaporation characteristics: A comparative analysis, Fuel 269 (2020) 117115 .

[37] O. Rybdylova, M. Al Qubeissi, M. Braun, C. Crua, J. Manin, L.M. Pickett, G. de Sercey, E.M. Sazhina, S.S. Sazhin, M. Heikal, A model for droplet heating and its implementation into ANSYS Fluent, Int. Comm. Heat and Mass Transfer 76 (2016) 265-270.

[38] O. Rybdylova, L. Poulton, M. Al Qubeissi, A.E. Elwardany, C. Crua, T. Khan, S.S. Sazhin, A model for multi-component droplet heating and evaporation and its implementation into ANSYS Fluent, Int. Comm. Heat and Mass Transfer 90 (2018) 29-33.

[39] S.S. Sazhin, M. Al Qubeissi, R. Nasiri, V.M. Gun'ko, A.E. Elwardany, F. Lemoine, F. Grisch, M.R. Heikal, A multi-dimensional quasi-discrete model for the analysis of Diesel fuel droplet heating and evaporation, Fuel, 129 (2014) 238-266. 
[40] M. Al Qubeissi, S.S. Sazhin, J. Turner, S. Begg, C. Crua, M.R. Heikal, Modelling of gasoline fuel droplets heating and evaporation, Fuel, 159 (2015) 373-384.

[41] F.P. Incropera, D.P. DeWitt, Introduction to Heat Transfer, fourth ed., John Wiley \& Sons, 2002.

[42] B. Abramzon, S.S. Sazhin, Convective vaporization of fuel droplets with thermal radiation absorption, Fuel 85 (2006) 32-46.

[43] C. Yaws, C, Gabbula. Handbook of Thermodynamic and Physical Properties of Chemical Compounds. Knovel; 2003. 


\section{Figure captions}

Fig. 1 Scheme (a) and a general view (b) of the experimental setup used in our analysis.

Fig. 2 The key steps in the analysis of the results obtained using the LIP method and mapping of the temperature field of a Diesel fuel droplet.

Fig. 3 The calibration curves for the LIP method for four liquids under consideration: water (WA), kerosene (KE), Diesel (DI), and gasoline or petroleum oil (PO): (a) $R_{1}$ versus temperature in ${ }^{\circ} \mathrm{C}$; (b) $R_{1} / R_{0}$ versus temperature in ${ }^{\circ} \mathrm{C}$, where $R_{0}$ is the value of ratio $R_{1}$ at temperature equal to $20^{\circ} \mathrm{C}$.

Fig. 4 Illustration of the formation of inhomogeneous concentration and agglomeration of BAM:Eu particles in a Diesel fuel droplet of volume about $8 \mu \mathrm{l}$ (corresponding to the initial droplet radius of $1.25 \mathrm{~mm}$ ) during its heating and evaporation in a flow of air at temperature $300^{\circ} \mathrm{C}$ and velocity 3.5 $\mathrm{m} / \mathrm{s}$. Left: the image for the channel $420 \mathrm{~nm}$. Right: the temperature field inferred from this image.

Fig. 5 (a) The rate of average droplet temperature growth $\left(W_{h}\right)$ versus boiling temperatures of the liquids under consideration for four ambient air temperatures. (b) Maximal values of $W_{h}$ for the liquids under consideration for which the distributions of temperature inside droplets using the LIP method were obtained; the values of ambient air temperatures for which the relevant $W_{h}$ were obtained are indicated. The initial droplet radii were 1.25 $\mathrm{mm}$ and ambient air velocities were $3.5 \mathrm{~m} / \mathrm{s}$.

Fig. 6 (a) The changes in the brightness for channel $455 \mathrm{~nm}$ of an evaporating Diesel fuel droplet of volume $8 \mu \mathrm{l}$ (corresponding to the initial droplet radius of $1.25 \mathrm{~mm}$ ) up to its maximal value (4096 counts). (b) The corresponding changes in the temperature field. Ambient air temperature and velocity were $200^{\circ} \mathrm{C}$ and $3.5 \mathrm{~m} / \mathrm{s}$, respectively.

Fig. 7 The changes in the kerosene droplet average temperature and the corresponding distributions of temperature during droplet oscillation. Am- 
bient air temperature and velocity were $200^{\circ} \mathrm{C}$ and $3.5 \mathrm{~m} / \mathrm{s}$, respectively. Droplet initial volume was $8 \mu \mathrm{l}$ (corresponding to the initial droplet radius of $1.25 \mathrm{~mm})$.

Fig. 8 Kerosene droplet average temperature inferred from thermocouple measurements and averaging the results of LIP measurement for the central area of the droplets and the corresponding distributions of temperature in a droplet placed in ambient air at temperature and velocity equal to $200^{\circ} \mathrm{C}$ and $3.5 \mathrm{~m} / \mathrm{s}$, respectively. Droplet initial volume was $8 \mu \mathrm{l}$ (corresponding to the initial droplet radius of $1.25 \mathrm{~mm}$ ). Case \#1 shows the original distribution of temperature predicted by the LIP method; Case \#2 shows the distribution of temperatures after the application of the correction based on the Sliding Average function.

Fig. 9 The temperature distribution inside a kerosene droplet heated in an air flow of velocity $3.5 \mathrm{~m} / \mathrm{s}$ and at temperatures in the range $100-500^{\circ} \mathrm{C}$ obtained using the LIP method. The droplet volume was about $8 \mu$ l, which corresponds to its initial radius $1.25 \mathrm{~mm}$.

Fig. 10 The plots of droplet surface temperatures versus time predicted by the Effective Thermal Conductivity (ETC) model (solid curves)and Infinite Thermal Conductivity (ITC) model (dashed curve) assuming that ambient air temperature and velocity are equal to $300^{\circ} \mathrm{C}$ and $3 \mathrm{~m} / \mathrm{s}$, respectively. Empty circles show the actual experimental results, while filled stars show the averaged values of droplet surface temperature inferred from experimental data. Figures $a, b, c$ and $d$ refer to water, kerosene, Diesel fuel and gasoline fuel droplets, respectively. The initial droplet radii for these droplets were $1.54 \mathrm{~mm}, 1.16 \mathrm{~mm}, 1.175 \mathrm{~mm}$ and $1.12 \mathrm{~mm}$, respectively. 


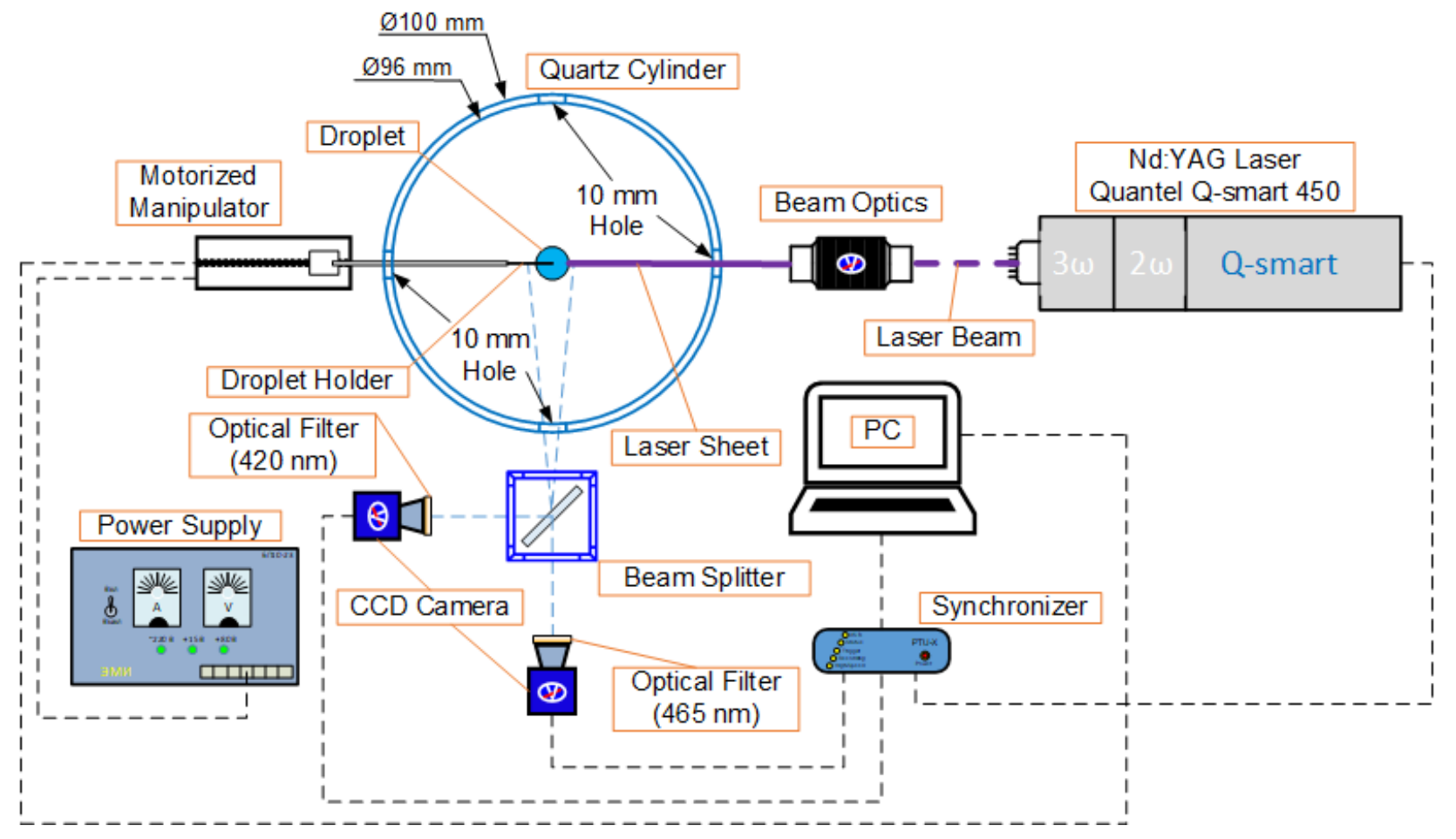

a

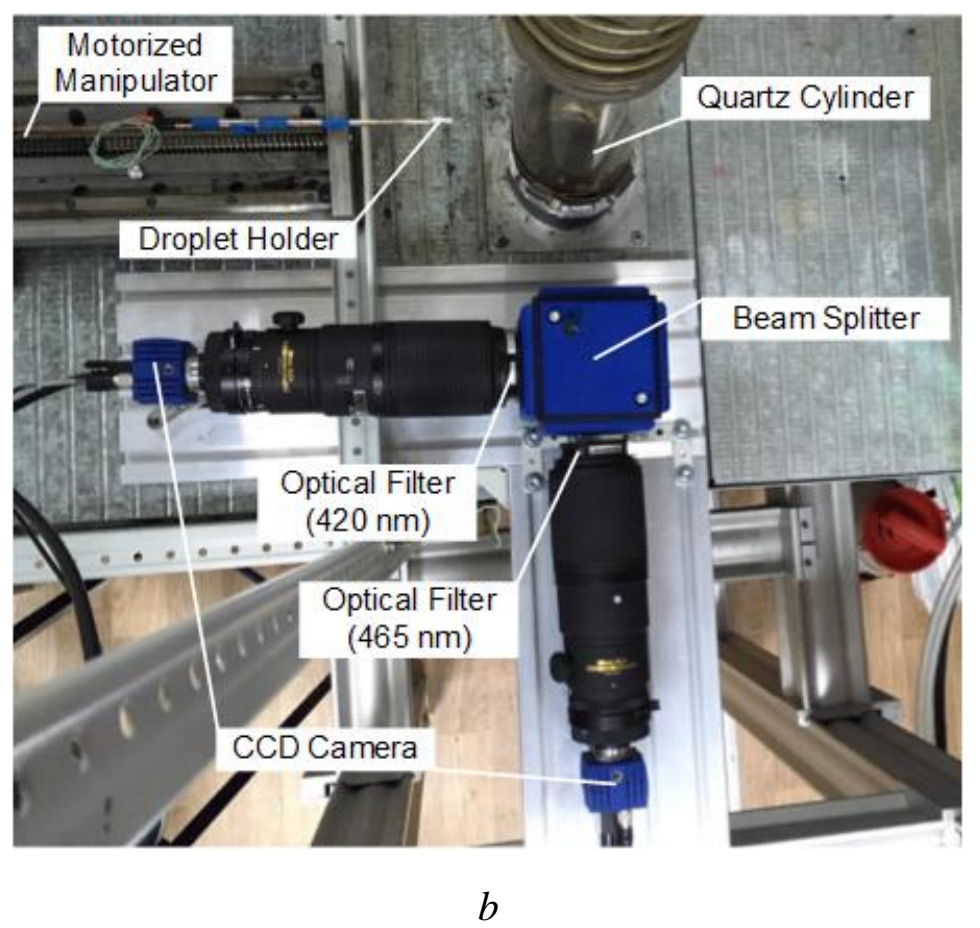

Fig. 1 


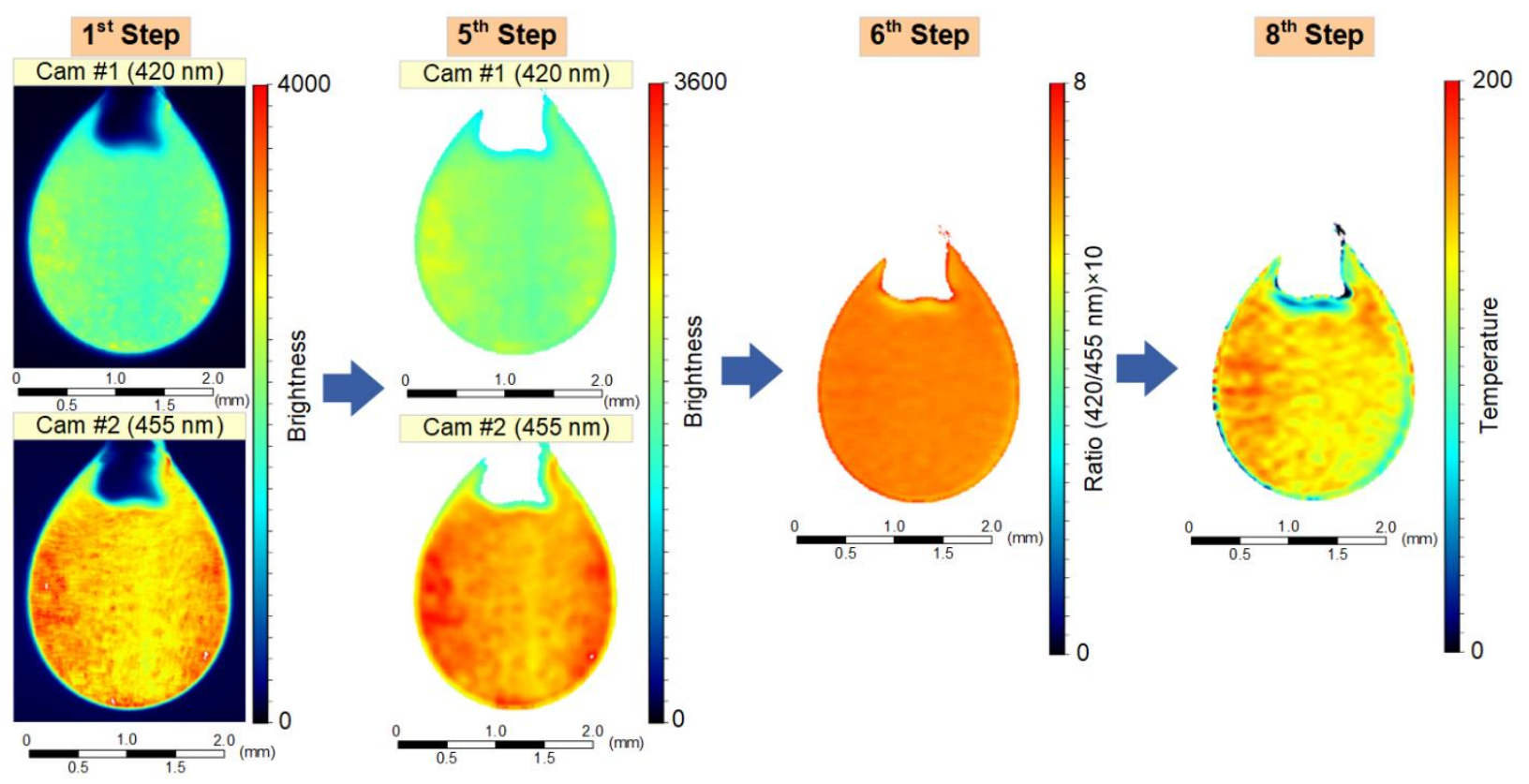

Fig. 2
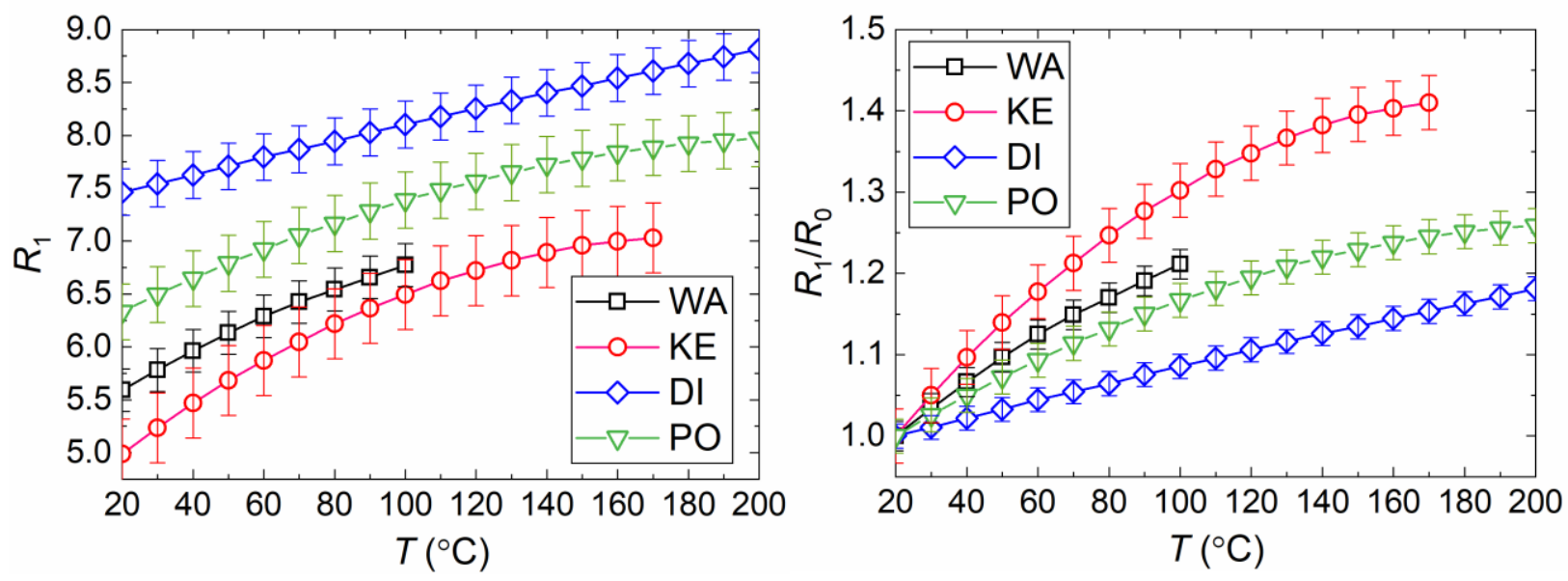

a

b

Fig. 3 


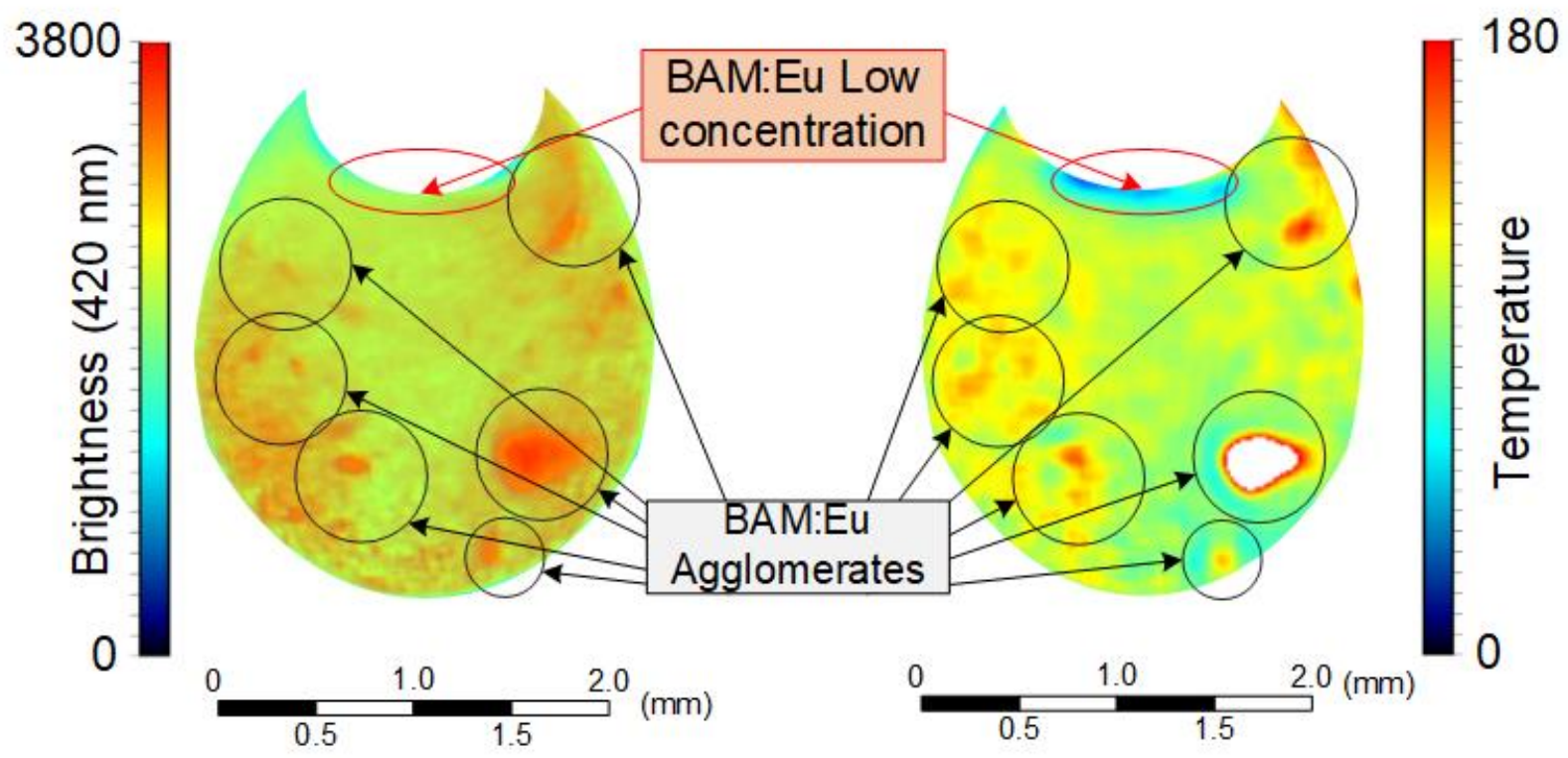

Fig. 4

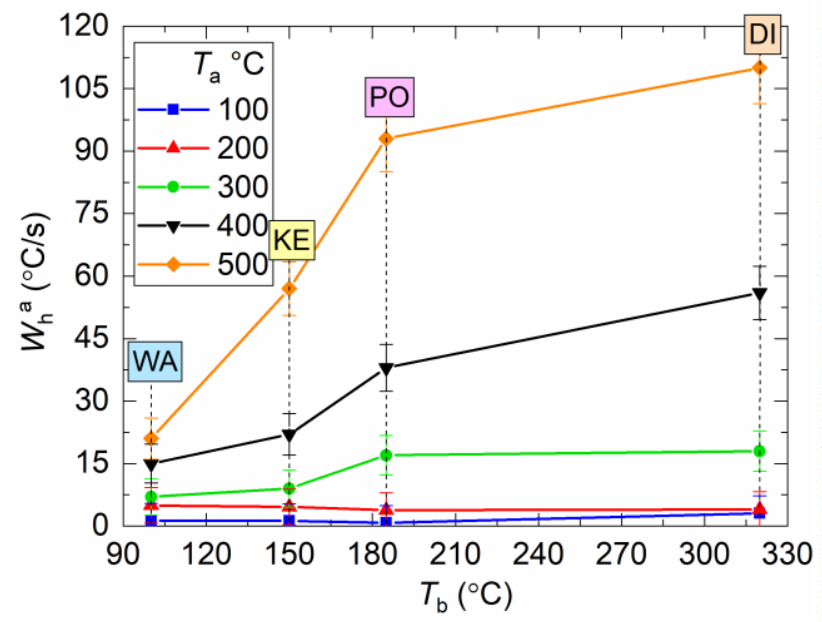

a

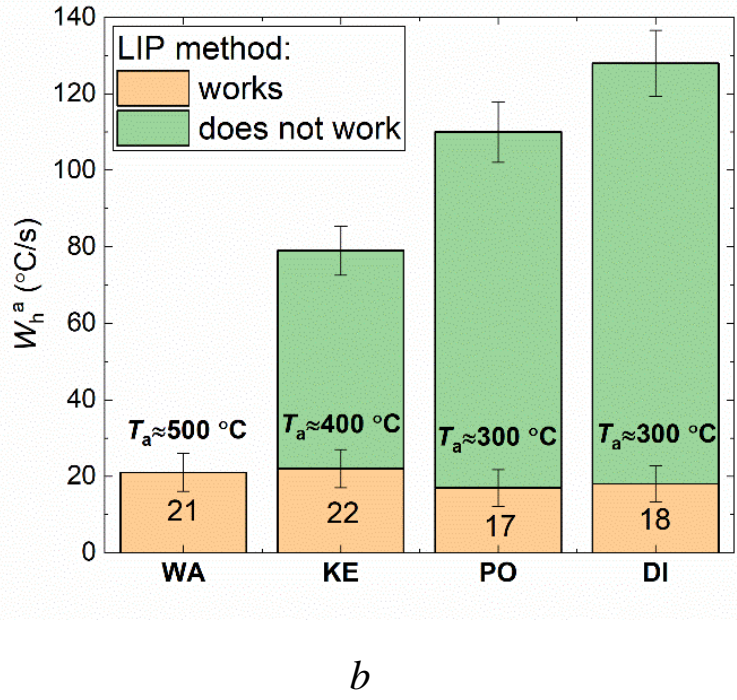

Fig. 5 


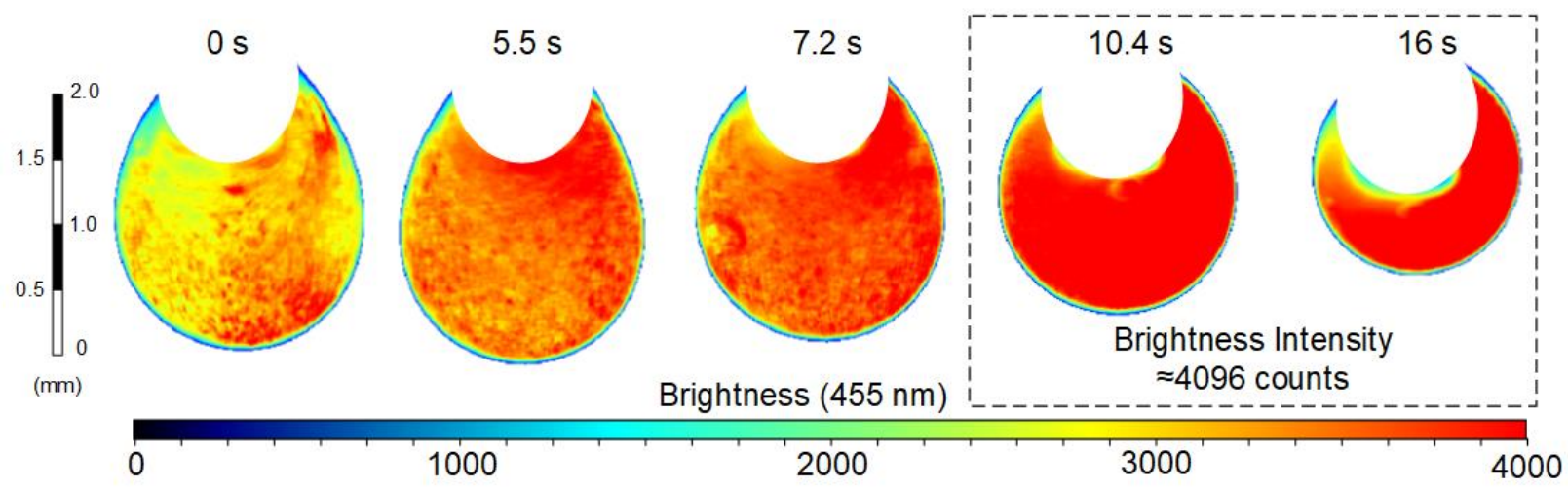

a

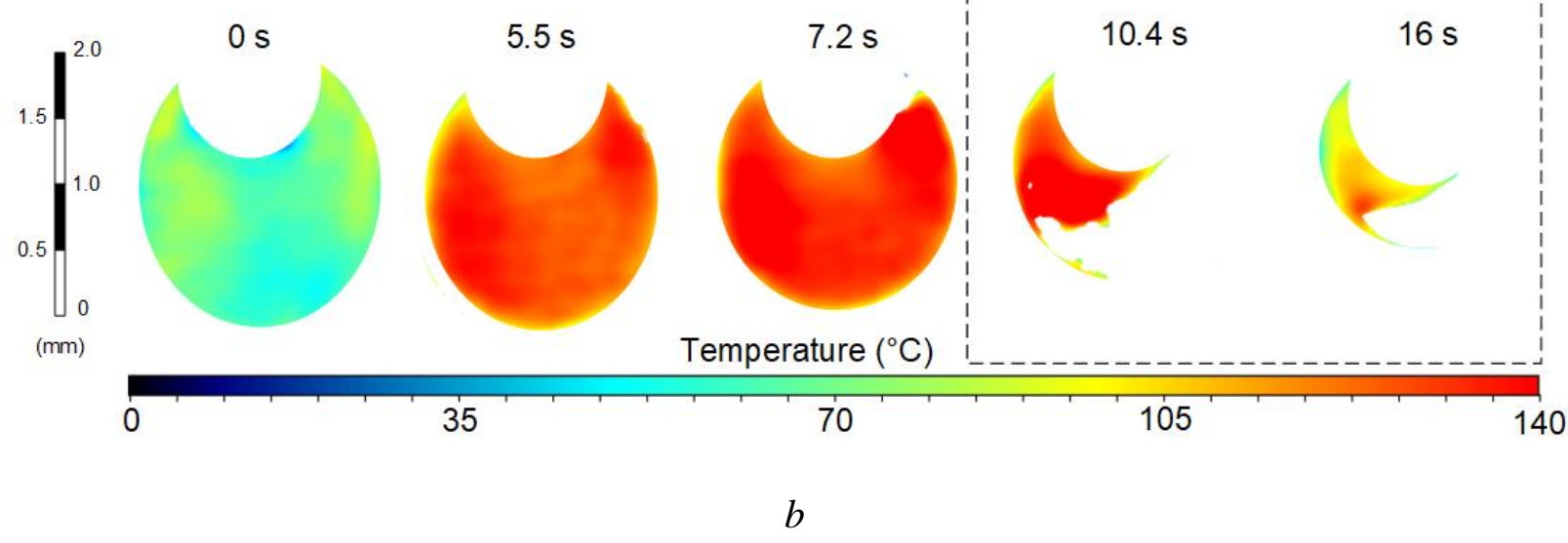

Fig. 6 

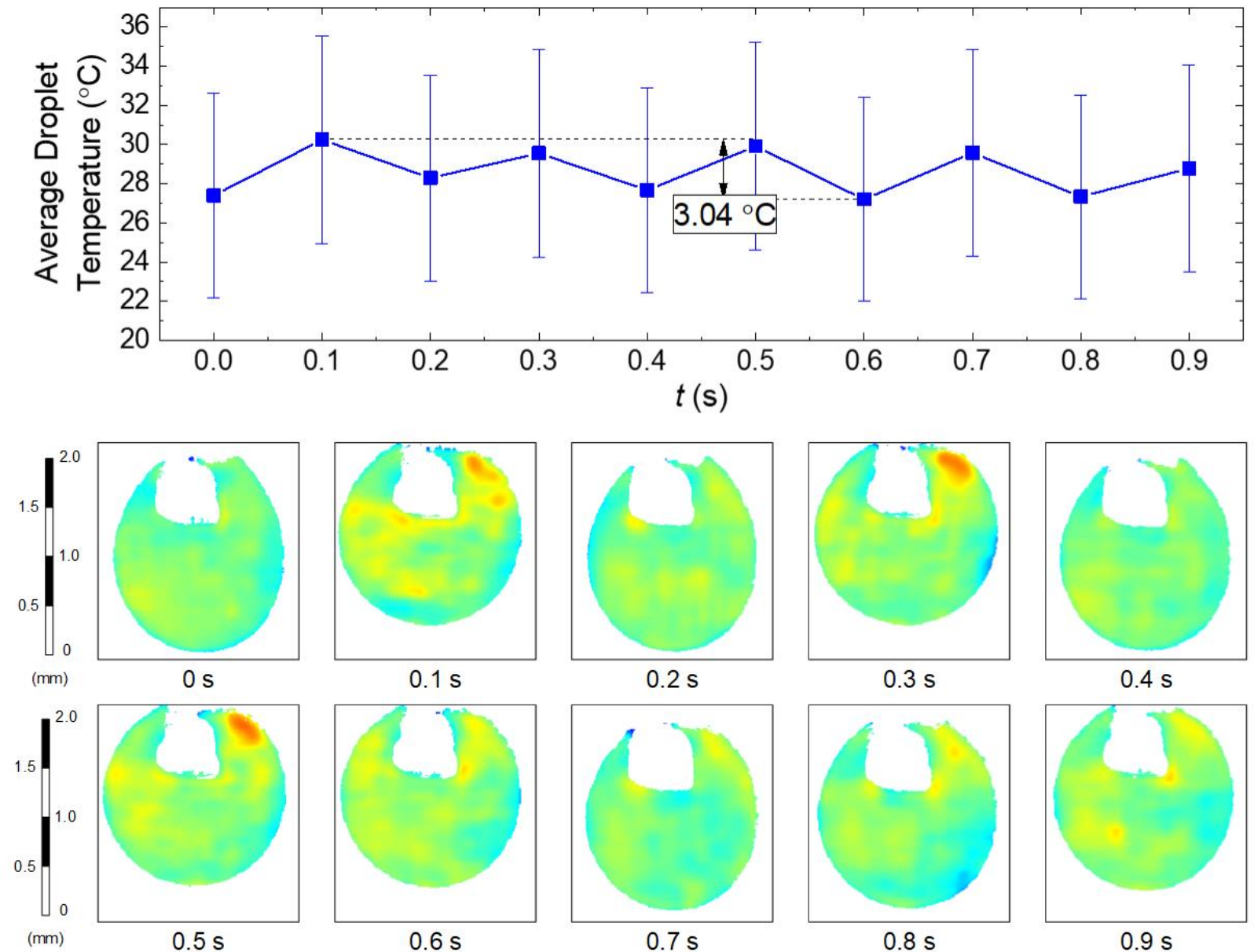

Fig. 7 

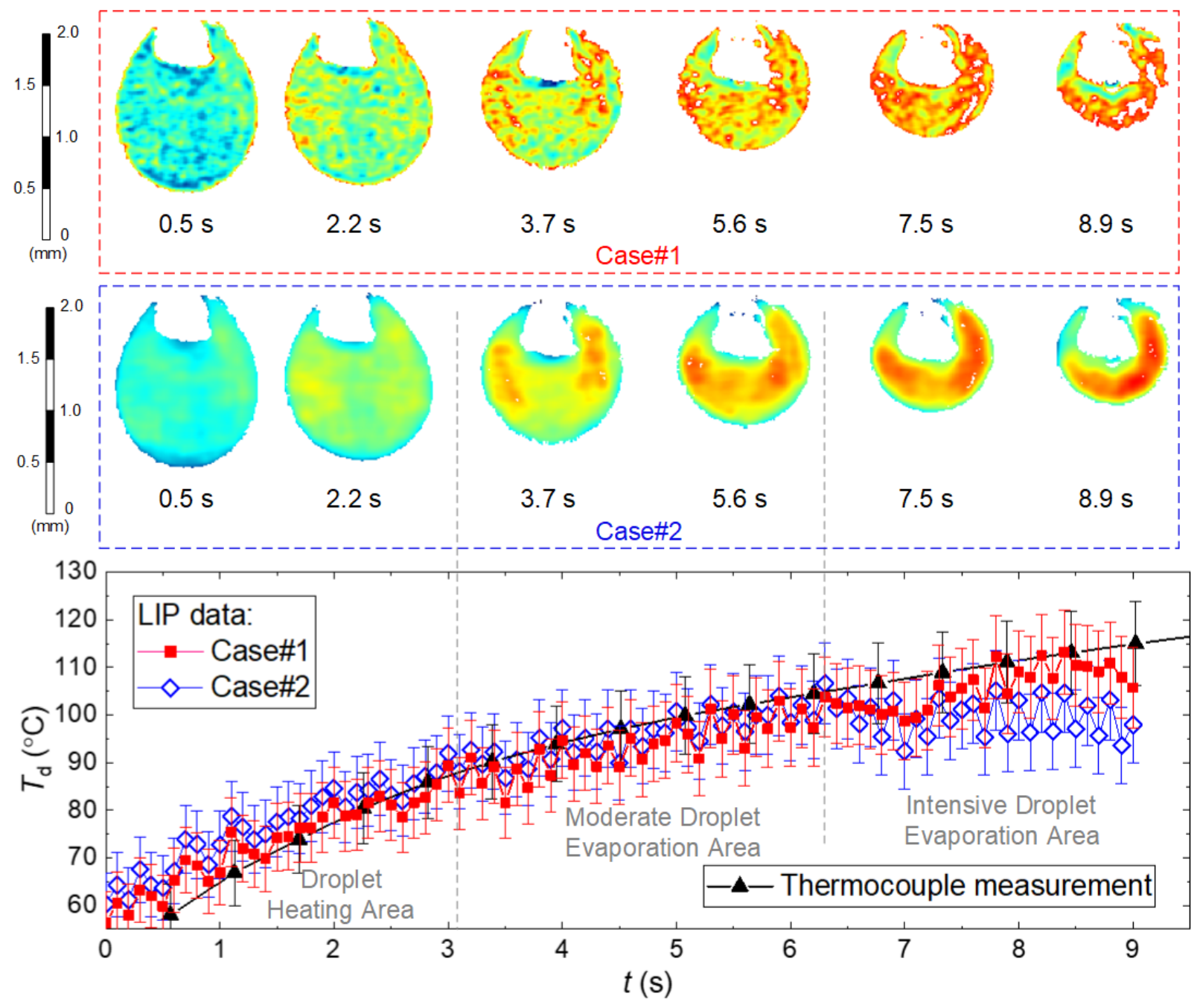

Fig. 8 

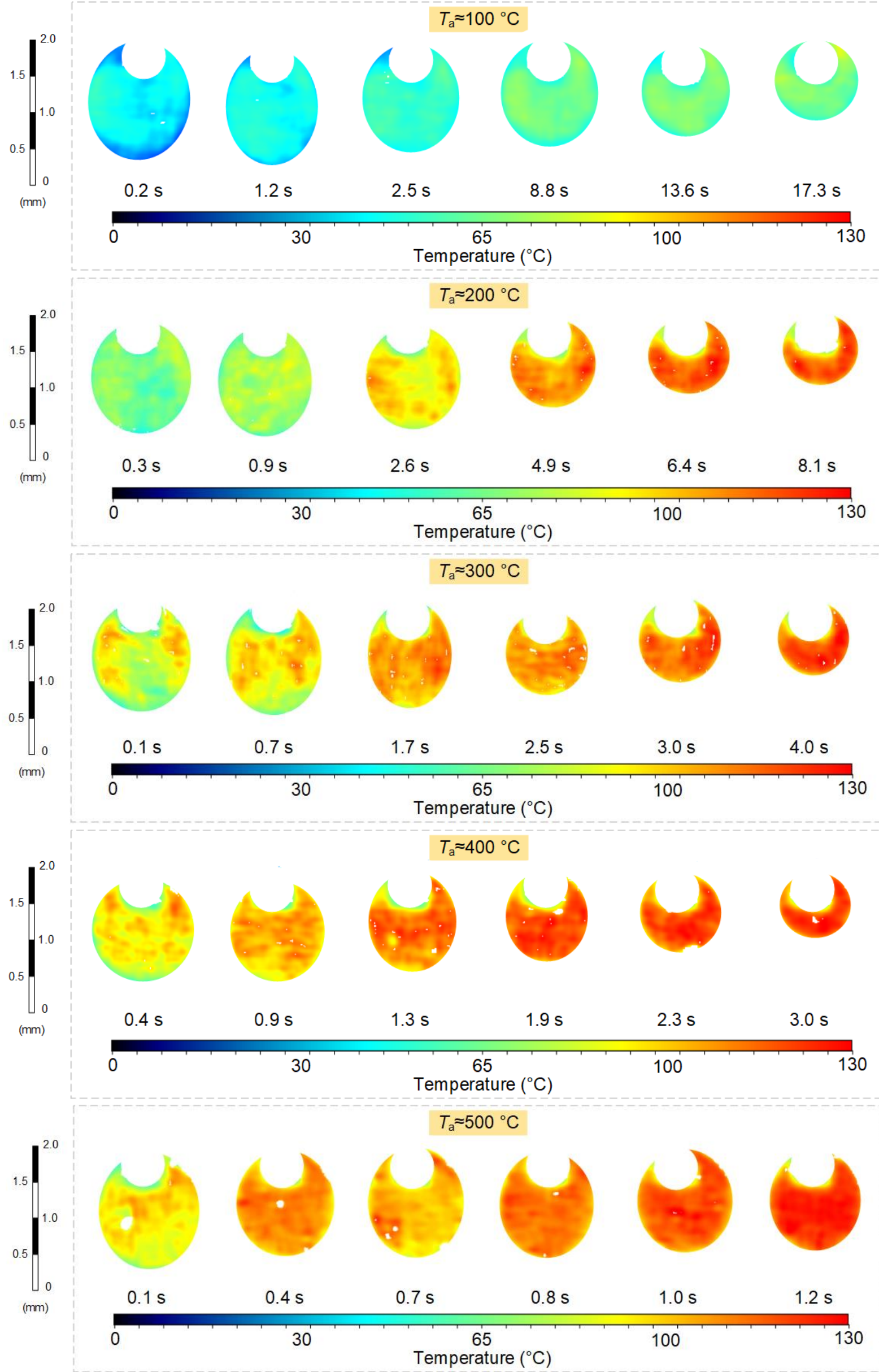

Fig. 9 


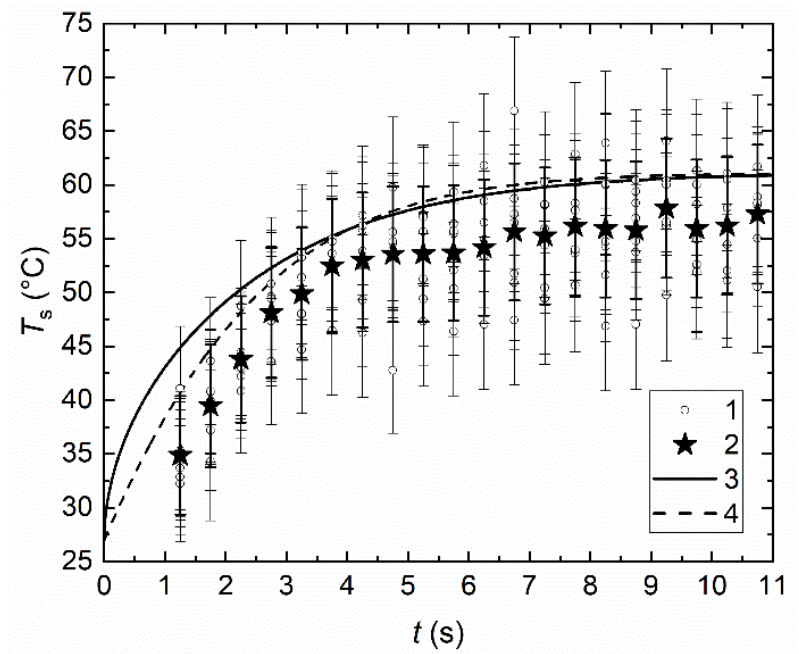

$a$

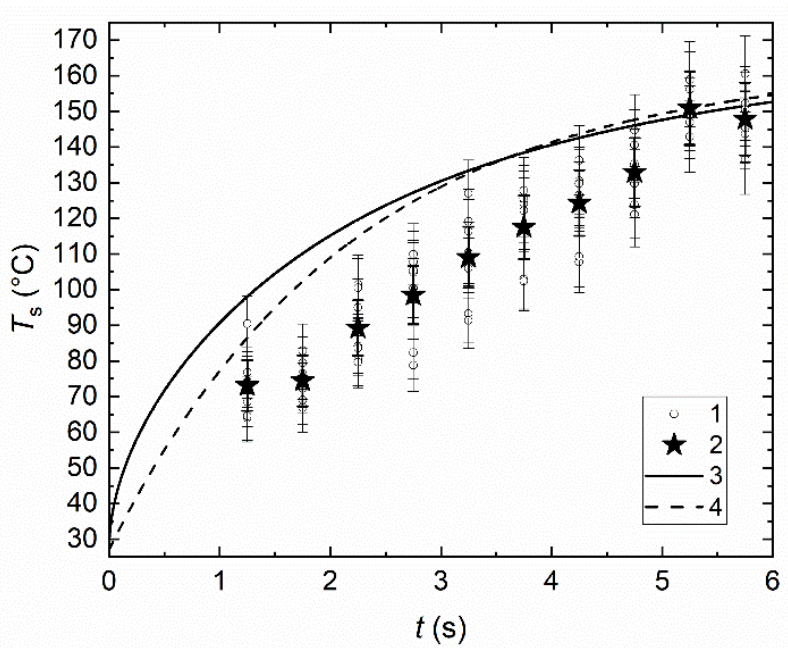

c

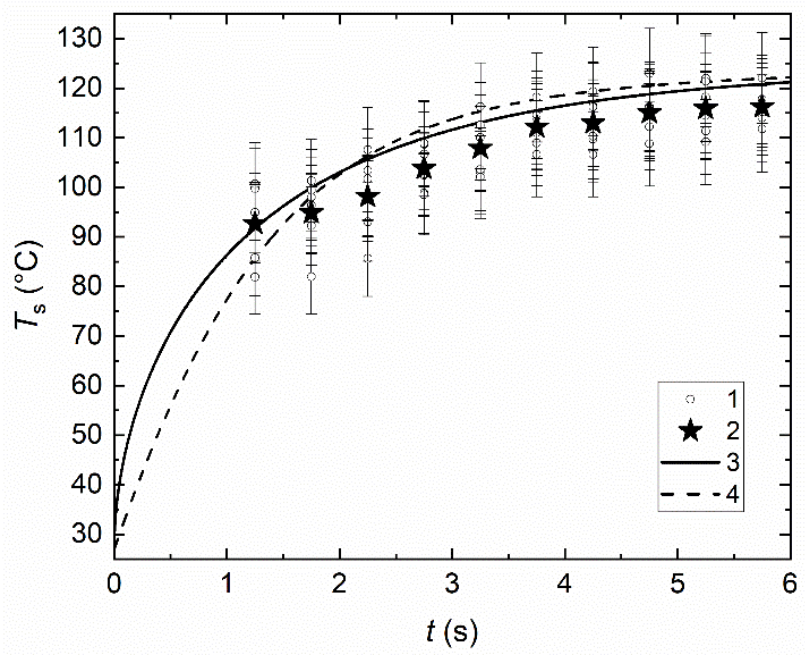

b

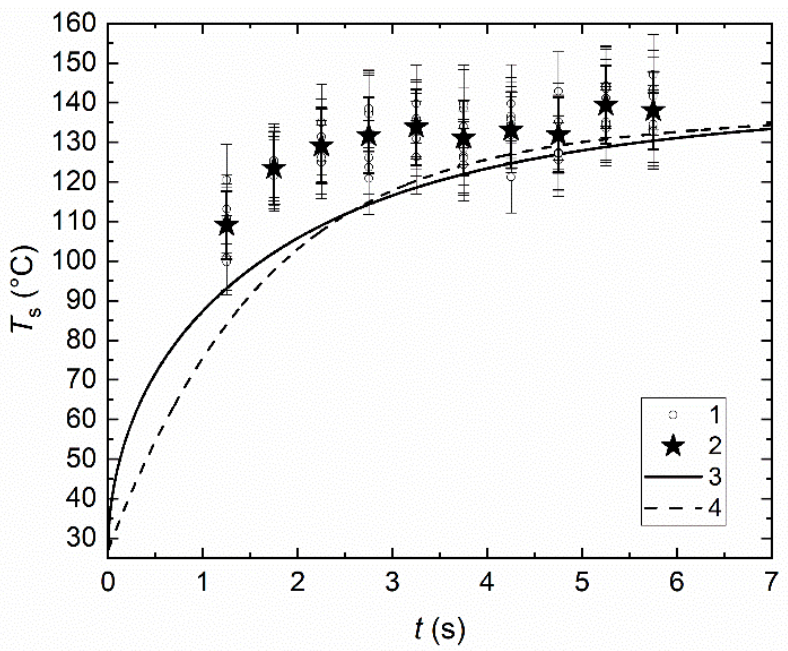

$d$

Fig. 10 